\title{
The Use of E-mail Marketing in
} Accordance With Permission Marketing Approach in Promotion of a Study Program

\author{
Aleksandar Grubor \\ University of Novi Sad, Faculty of Economics in Subotica, Subotica, Republic of Serbia \\ Nenad Djokic \\ University of Novi Sad, Faculty of Economics in Subotica, Subotica, Republic of Serbia \\ Nikola Milićević \\ University of Novi Sad, Faculty of Economics in Subotica, Subotica, Republic of Serbia
}

\begin{abstract}
The use of e-mails for promotion has been in place for decades. A large number of e-mails received by consumers and potential consumers are not requested by them and in most cases do not provide adequate value for them. In that sense, the permission marketing approach brings in multiple novelties. The sender of the promotional message strives at all stages of the relationship with potential and current consumers to obtain permission to communicate with them and to communicate the appropriate value. Within these phases - attract, convert, close and delight - e-mail marketing takes a significant place. The use of this approach is possible and desirable when higher education institutions are concerned as well. In this paper, several goals are set. First of all, it points to the specific features of permission marketing, the phases of its implementation, and various instruments that are adequate for applications in different phases. Thereafter, general recommendations for the promotion of higher education institutions in accordance with that approach, with special emphasis on email marketing, are provided. Finally, an example of promotion with using the e-mail and referring to the selected study program of the domestic higher education institution, precisely in accordance with the permission marketing approach, was presented.
\end{abstract}

\section{Keywords}

Permission marketing, e-mail marketing, promotion, higher education institutions, study program.

\section{Introduction}

Although the use of e-mails for promotion has been in place for decades, a large number of emails received by consumers and potential consumers are not requested by them and in most cases do not provide adequate value for them. With regard to the above mentioned situation, the permission marketing approach brings in multiple novelties reflecting primarily in the fact that the sender of the promotional message strives at all stages of the relationship with potential and current consumers to obtain permission to communi- cate with them and to communicate the appropriate value. Within these phases - attract, convert, close and delight - e-mail marketing takes a significant place. The use of this approach is possible and desirable when higher education institutions are concerned as well.

Bearing the above in mind, several goals are set in this paper:

- point to the specific features of permission marketing, the phases of its implementation, and various instruments that are adequate for applications in different phases, 
- provide general recommendations for the promotion of higher education institutions in accordance with that approach, with special emphasis on email marketing,

- present an example of promotion using email and referring to the selected study program of the domestic higher education institution, precisely in accordance with the permission marketing approach.

In addition to the overview of relevant secondary sources, the paper also presents an example from domestic practice.

\section{Permission marketing}

The foundations of permission marketing can be identified in the work of Seth Godin, who published Permission Marketing: Turning Strangers into Friends and Friends into Customers Hardcover in 1999. In his book, he points to the increasing lack of attention of the target auditorium in mass media action, enormous growth of costs to attract this attention, but also a certain degree of failure of such attempts. It is such promotion, which he terms interruption marketing, that he contrasts to permission marketing.

The author explains the difference through a figurative story about how it is possible to get married in two ways. The first way suits marketers who use interruption marketing. Such a marketer buys the most expensive clothes, new shoes, the most fashionable accessories, and then, based on the best databases and marketing strategies, chooses a demographically ideal singles bar. In this bar, he approaches the nearest person and proposes marriage, and if he gets rejected, he repeats this process with every person in the bar. Having spent the whole evening in the bar without anyone consenting, it seems obvious to him that the suit and the shoes are to blame. Both the tailor and the strategist get dismissed. Then the marketer repeats his attempts, but at another singles bar. On the other hand, the marketer who uses permission marketing opts for dating. He goes on a date, and if it goes down well, they go to the next one, and the next. After a dozen dates, both sides can really communicate their needs and wishes, then sometime around the twentieth date, their family members meet, and finally, after three or four months, the marketer proposes marriage.

It is clear from the above story that acting in the case of permission marketing approach is significantly different. The author separates the process into five steps:
1. offer the potential consumer reasons for paying attention - from information, through entertainment and contests, even down to payment - the incentive must be open, obvious and delivered clearly;

2. inform the potential customer about the product, that is, its advantages;

3. intensify incentives, which is facilitated by the existence of bilateral dialogue;

4. increase the level of permission that the seller receives from the potential customer, e.g. gathering more data about the customer's private life, hobbies or interest; offer new product category or its samples;

5. use the permission in a win-win situation.

Krishnamurthy (2001) gives a conceptual framework for cost and benefit analysis related to customer experience in permission marketing programs. The customers' interest is viewed as the key variable affecting the participation level. On the other hand, the customer experience itself is positively determined by the significance of the message and monetary benefits, and negatively by the forfeit for receiving/modifying information, for processing and privacy issues.

Tezinde, Smith and Murphy (2002) conclude that customer response to a campaign devised in accordance with permission marketing is affected by: relevance - personalization, brand equity, and previous relationships. The influence of demographic variables showed itself as weak, and the existence of interaction between independent variables was not established either.

Shukla (2010) identifies spread velocity, hits/download, attitudinal shift, believability, public relations, data capture, penetration level, turnout, shock level, reachability, awareness and campaign persistence as key parameters for developing an effective viral and permission-based internet campaign.

Opreana and Vinerean (2015) point to the significance of this approach in the conditions of prominent presence of electronic business, terming it inbound marketing. Comparing such digital marketing with traditional marketing, they identify interactivity and engagement. They define it as "the process of reaching and converting qualified consumers by creating and pursuing organic tactics in online settings". Within this approach, they identify 4 components: brand-focused marketing communication, marketing content, social media marketing and search engine optimization. 
Presenting the elements of this approach on behalf of Hubspot company, which rates among the world's most prominent in software generated based on it, Bernazzani (2018) points out that one undergoes the attract, convert, close, delight phases evolving from stranger, through visitor, potential customer and customer all the way to promoter. Whereas the roles of blogs, landing pages and internet sites are more significant fore-mail gathering in the first phases, they can even be gathered through social networks, while e-mails gain importance in later phases.

\section{E-mail marketing within the promotion of higher education institutions in accordance with permission marketing approach}

The above mentioned company, Hubspot, issued two sets of guidelines (Nicholson, 2016; Hubspot, n.d.) about how to use e-mail marketing within promotion of educational institutions in accordance with permission marketing approach. At this point, recommendations found in those two sources are sublimated. In addition, certain recommendations adapted to domestic condition are given.

As far as the promotion of a certain study program is concerned, it is first necessary to consider the entirety of communications conducted by the institution where this program is realised. In this sense, it is extremely important to know, understand and apply the concept of integrated marketing communications, pointing to the need of sending a consistent promotional message through all communication channels, where synergetic effects are achieved owing to the existence of several channels through the message is transmitted. The implications of the above can be multiple. On the one hand, the promotion of the study program becomes the part of promotion of the institution and another manner of transmitting promotional messages pertaining to it and its offer. On the other hand, the promotion of the study program itself should send a consistent message through several media and achieve synergetic effects, that is, feature as integrated communications.

The first phase of conducting e-mail marketing campaign includes attracting potential customers to leave their e-mail addresses through which communication with them can be achieved. In the specific example of study program promotion, it is possible, as it were, to perform this gathering in two ways: one is offline, and the other is online approach. An example of the former can be visits by appropriate teams consisting of teaching staff and/or students to schools, where they would give presentations and gather e-mail addresses from the interested secondary school students, as well as permissions to communicate with them in this manner. This approach would also include visits of the interested candidates on open-door days, certain free lectures at secondary schools, etc. The latter aspect refers to online contents that can be offered on site about the study program, including certain blogs, Facebook profiles etc, where e-mail addresses could also be collected.

The key question in this phase is what the contents that should be presented to potential customers are. On the one hand, as an utterly ethical approach, it would be necessary to promote the study program and the institution explicitly. However, one must bear in mind that a future student does not buy only that. In addition to the contents and characteristics of the study program and higher education institution, as well as contents closely related to them, such as employment opportunities, earnings of the alumni, recognition of the diploma abroad, one must also consider all other characteristics of life that the potential student will have. This includes sightseeing of the city, social life, down to particular technical details. On the other hand, through the study program, students must fulfill their wish to acquire knowledge in particular areas, so that the offer of contents related to this knowledge is another desirable segment of the appeal phase.

A special aspect for consideration is to whom all the above mentioned should be addressed. In this sense, different roles in the purchase process should be taken into account. Although the students are undeniably defined "consumers" of the study program, it can be assumed that the persons of influence, among others, include their parents. In connection with this, it is particularly important to consider carefully whether a certain campaign should be targeted at them, which appeals should be used, and how all the elements should be integrated.

In the recommendations given by Hubspot, the following phases are mentioned:

- awareness (when future students or their parents become aware of their need and/or desire for an institution of the kind that is being promoted, that is, for a similar type of education), 
- consideration (when the potential student or his/her parent has clearly defined the problem), and

- decision (when the potential student or his/her parent has made a decision on the strategy, method, and approach to solving the problem and strives to focus their choice).

Various educational resources are recommended in the first phase:

- blogs and articles,

- free instructions,

- video footage,

- checklists,

- posts on social networks.

The recommended approach for the second phase is to provide detailed information on the institution and the way it can resolve the students' challenges and enhance the opportunities. What is recommended is distribution of:

- webinars,

- virtual tours,

- career advice,

- profiles of current students and alumni.

In the third phase, it is recommendable to distribute:

- schedules of important dates,

- scheduling appointments through websites,

- consulting sessions with professors.

Following the above described "customer track", certain time-related recommendations are given across individual phases. For instance, the following is recommended in the awareness phase:

- 2 years before enrolment, distributing materials about what is assessed or examined at the entrance exam, so that candidates can have time to prepare,

- 1 year before enrolment, offering the opportunity for asking questions and receiving answers from current students.

In the consideration phase, the recommendations are:

- 6 months before enrolment - sending important dates,

- 1 month before enrolment - schedules of possible consulting sessions about entrance exams.
In the decision phase, it is recommended to:

- send a reminder e-mail 1-2 days beforeenrolment,

- send a welcome e-mail after enrolment.

The use of the following is recommended in creating the various above mentioned contents:

- current students (e.g. "What would I like to have known before coming to the college?", "10 best hidden spots for studying" and "7 cool lectures you simply must visit",

- alumni ("Your most important experiences before graduation", "What did I do for the subsequent 4 years?" and "10 steps in preparation for life after graduation"),

- professors and department heads (how the lectures are taught, what was done within the courses earlier)

- student services (" 10 best tips before the entrance exam", "Questions to ask on open door day" and "What to expect from various study programs?"

In the context of the above points, it is recommended to send the following types of mails to lists that should be segmented according to appropriate criteria:

- helpful resources,

- newsletters,

- important dates,

- information on courses,

- offer to connect.

When it comes to e-mails, the following 10 recommendations are given:

1. subject: clear, attention catching,

2. sender: a person with full name,

3. branding: some kind of institution branding,

4. personalisation of the message: necessary,

5. timing: the right time of day for the target audience,

6. value: clear value proposition,

7. call to action: single, clear, focussed,

8. sharing through social networks: yes, for important events,

9. second call to action: if required, at the end of the mail or in post scriptum,

10. cancellation: leave a link with privacy policy and possibility to cancel receiving further mails. 
It must also be mentioned that there is a very important point, the so-called nurturing potential customers. The example given in the above mentioned literature refers to a "smart list", comprised of people six months before the enrolment, who download a report on life on campus and perform a certain number of visits on the web page about student life. This can result in a range of mails. The first one can be sent two days after these conditions have been fulfilled, and would contain the school's latest report on students' life. The second would be sent 10 days after the first, and would contain a list of sources about activities on the campus and in student groups. The third e-mail would be sent 15 days after the second, and would include a link for virtual tour, while the fourth would be sent 10 days after the previous one, with an invitation to visit the campus.

\section{An example from domestic practice}

Starting from the above principles, a campaign has been partly completed, and partly is still in progress, by the study program of Marketing of the Faculty of Economic in Subotica, with the assistance of the Centre for Marketing in Novi Sad and Centre for Marketing in Subotica, during a part of the lecture process on relevant courses from the specialised area of Marketing. Realisation of the campaign was approved by the institution's management, and was fully complementary with the entire enrolment campaign.

The current students of the Marketing study program first needed to be trained in basics of email marketing, for which a tutorial provided by Hubspot was used, and which offers a free certificate. In addition, realisation of the campaign requires the proficiency in appropriate tools, and in this specific case, the tutorial was prepared by the course professor for Mailchimp. Earning such references - certificate, training in the above mentioned tool and participation in planning, conduct and evaluation of the campaign - the students themselves build their own future competitive advantage on the labour market.

Gathering email addresses was done dually during visits to schools where the representatives of the student organisations gave lectures, and uploading online contents, which requires providing an email address for additional reading.

Design of the campaign should follow the recommendations described in the previous section of the paper, adapted to domestic conditions. The direct communication resulted in the conclusion that preparation for the entrance exam begins much later than the above mentioned recommendations suggest, but it is possible to communicate all the necessary elements of student life even in this timeframe.

The campaign formally ends at the point of enrolment, but communication with the studentsneeds to be continued after that date as well, suggesting the value of choice and possibly transforming them into the ambassadors of the institution and study program in subsequent campaigns.

\section{Conclusion}

This paper presents three interconnected topic. First of all, the specific features of permission marketing are described, both through the work of its founder Seth Godin and through the overview of other secondary sources. The phases of its implementation were also presented, as well as highlighting the adequacy of various instruments in the context of various phases, and pointing to the position of e-mail marketing in this process.

The second section of the paper offers recommendations for promoting higher education institutions in accordance with permission marketing approach. Although the key focus was on e-mail marketing, the paper also presents a range of possibilities in the development of a campaign for enrolment of students in the context of various phases through which potential customers pass, as well as the timeframe.

Finally, the paper presents an example of email promotion of the Marketing study program of the Faculty of Economics in Subotica, particularly in accordance with permission marketing approach. What is also presented is the way of enabling current students to participate in such a campaign, and the relevance of acquired references.

In addition to the presentation of a modern approach to promotion, the paper is also significant from the aspect of a range of practical advice, not only concerning educational institutions, but also in the case of appropriate modifications, and a much larger number of market players.sm

\section{References}

Bernazzani, S. (2018). The Ultimate Guide to Customer Delight. Retrieved March 8, 2018 from Hubspot: https://blog.hubspot.com/customer-success/customerdelight.

Hubspot (n.d.). From Stranger to Student: A Marketer's Guide to Increasing Applications with Early Stage Conversions. Retrieved March 14, 2018 from Hubspot: https://offers.hubspot.com/from-stranger-to-student. 
Krishnamurthy, S. (2001). A Comprehensive Analysis of Permission Marketing. Retrieved March 8, 2018 from Journal of Computer-Mediated Communication, 6 (2) https://academic.oup.com/jcmc/article/6/2/JCMC623/45 84249.

Nicholson, J. (2016). Email marketing -for schools- Taking your prospects from Inbox to enrollment. Retrieved March 14, 2018 from Hubspot:

https://offers.hubspot.com/email-marketing-forschools? ga $=2.145562487 .255679655 .1521115777$ 517378288.1503172187.

Opreana, A., \& Vinerean, S. (2015). A New Development in Online Marketing: Introducing Digital Inbound Marketing. Expert Journal of Marketing, 3 (1), 29-34.

\section{$凶$ Correspondence}

\section{Nenad Djokic}

Faculty of Economics in Subotica

Segedinski put 9-11, 24000, Subotica, Serbia

E-mail: djokicn@ef.uns.ac.rs
Seth, G. (1999). Permission marketing: Turning strangers into friends and friends into customers. New York: Simon \& Schuster

Shukla, T. (2010). Factors Affecting 'Internet Marketing' Campaigns with Reference to Viral and Permission Marketing. The IUP Journal of Management Research, 9 (1), 26-37.

Tezinde, T., Smith, B., \& Murphy, J. (2002). Getting permission: Exploring factors affecting permission marketing. Journal of Interactive Marketing, 16 (4), 28-36. 